Article

\title{
Social Relationships and the Health of Older Adults: An Examination of Social Connectedness and Perceived Social Support
}

Samuel Asante ${ }^{1, *(D)}$ and Grace Karikari ${ }^{2}$

check for updates

Citation: Asante, S.; Karikari, G. Social Relationships and the Health of Older Adults: An Examination of Social Connectedness and Perceived Social Support. J. Ageing Longev. 2022, 2,49-62. https://doi.org/10.3390/ jal2010005

Academic Editor: Laurie Buys

Received: 13 November 2021

Accepted: 11 February 2022

Published: 2 March 2022

Publisher's Note: MDPI stays neutral with regard to jurisdictional claims in published maps and institutional affiliations.

Copyright: (c) 2022 by the authors. Licensee MDPI, Basel, Switzerland. This article is an open access article distributed under the terms and conditions of the Creative Commons Attribution (CC BY) license (https:// creativecommons.org/licenses/by/ $4.0 /)$.
1 Department of Social Work, Northeastern State University, Broken Arrow, OK 74012, USA

2 Department of Population Health, University of North Dakota, Grand Forks, ND 58202, USA; grace.karikari@und.edu

* Correspondence: asante@nsuok.edu; Tel.: +1-918-449-6537

\begin{abstract}
This study examined the extent to which dimensions of social connectedness and perceived social support have distinct associations with the physical and mental health of older adults. This study utilized data from the Utah Fertility, Longevity, and Aging (FLAG) study. Participants included 259 older adults, aged 60 or older (mean age: $67.75 \pm 4.8$ ). Connectedness (networks and satisfaction with networks) was measured with the Duke Social Support Index. Social support (affective, confidant, instrumental) was measured with the Duke-UNC Functional Support Scale. Physical and mental health were measured with the Short Form Health Survey (SF-36). The results showed significant differences in the mean physical and mental health scores between participants with high scores on satisfaction with networks, affective, confidant, and instrumental support, and those with low scores on these dimensions. After controlling for covariates, affective support significantly predicted physical health, while satisfaction with networks, and affective and instrumental support significantly predicted mental health. The findings suggest that social support may be relatively more important to the health and wellbeing of older adults than social connectedness. This underscores the relative importance older adults attach to the quality rather than quantity of social ties.
\end{abstract}

Keywords: social connectedness; social support; older adults; physical health; mental health

\section{Introduction}

Social relationships are fundamental to human survival and are significantly involved in the attainment and maintenance of good health and wellbeing. Social relationships have been variously defined and measured diversely across studies and disciplines. Regardless of the differences, however, two major components of social relationships have consistently been studied and documented: social networks and social support [1-3]. Studies have demonstrated a clear link between these components and the health of older people. For instance, strong ties with families and friends have been found to improve mental and physical health, positively influence health behaviors, reduce mortality risk [4-8], and enable older adults to stay in the community rather than being institutionalized [9]. Additionally, supportive relationships have been linked to the provision of emotional security [10]. With its absence often experienced as emotional (loneliness) and social isolation, older adults appraise their social relationships on the basis of the degree to which they feel connected and supported [5,11-13].

\subsection{Social Connectedness and Social Support}

Social connectedness and social support have not always been considered separately in previous studies. This is partly the result of their linear relationship, with social support being a function of social relations that are provided by members in one's social network. In most studies, for instance, having a companion was synonymous with social 
support $[3,14,15]$ regardless of whether or not support was provided. Again, studies examining isolation and loneliness have, to a large extent, been conducted in the context of social support $[4,16,17]$ where the availability of social support indicated the presence of social relations or ties and thus the absence of loneliness feelings. Some studies, however, suggest that the availability of companionship does not guarantee that social support will actually be provided [18-20].

Few studies on social relationships have examined the influence of isolated aspects of social relationships such as the total level of connectedness and the amount of social support on the health and wellbeing of older adults $[10,18,21,22]$. While this method is important and enlightening, there are theoretical and empirical reasons to suspect that adding up the individual aspects of relationships to create a unidimensional construct does not compare with the effect of being nested in a relationship construct with a particular set of characteristics (e.g., frequent interaction with family and friends or receiving emotional support). In other words, by examining social connectedness and social support as singular, non-dimensional constructs, it becomes difficult to distinctly identify the dimensions within each construct and their health implications, particularly among older adults for whom the importance of social relationships cannot be underestimated [18,23-25].

Dimensions of Social Connectedness and Social Support

Social connectedness is a measure of belongingness and interaction between people [12]. It involves the quality and the quantity of ties one has with others in both familial and non-familial social circles [26,27]. Indicators of connectedness reported in the literature include the size of one's social network, and the frequency of interaction among network members and engagement in social activities [11,12].

Network ties are conduits of social support. Social support has been described as interpersonal exchanges involving the expression of a positive affect to another, the giving of material aid, and the provision of information relevant to one's self-evaluation [8]. Three major forms of social support have been studied and documented in the literature-affective or emotional, instrumental or practical, and confidant or informational support. Affective support is considered as the most important form of social support. It refers to the expression of love, sympathy, care, and trust, and the acceptance of an individual [8,25]. Instrumental support includes actions intended to help meet an individual's needs, such as providing financial assistance and offering shelter or services needed to enhance the living condition of an individual $[28,29]$. Confidant support refers to having a partner with whom secrets are disclosed or private matters discussed [25].

\subsection{Purpose of the Study}

In spite of the empirical evidence linking some of these dimensions of connectedness and social support to health, a limited number of studies (to the knowledge of the researchers) exist that simultaneously examine the dimensions of social connectedness and social support and their relationship with health $[7,19,21,28]$; thus, it is difficult to draw a firm conclusion on the health implications of dimensions of social connectedness and social support. It therefore may be more informative to examine some of these dimensions and their association with the physical health and mental wellbeing of older adults. To contribute to the existing research on social relationships and their impact on health of older adults, this study aimed to investigate the association of the dimensions of social connectedness (networks and satisfaction with networks) and perceived social support (affective, confidant, and instrumental) with the physical and mental health of older adults.

\section{Methods}

\subsection{Design and Sample}

Data for this study were obtained from the Utah Study of Fertility, Longevity, and Aging (FLAG). The FLAG study, an observational longitudinal study, comprises a statewide multiple statistical analysis of collected and existing medical and demographic records 
of geographically stable older adults. The FLAG project is premised on the hypothesis that a constellation of factors, both genetic and environmental, influence the rate of aging and longevity. The study attempted to test this claim by identifying families known to have exceptional longevity on whom to measure the epidemiologic, social, cognitive, psychological and molecular traits believed to be associated with aging and longevity (FLAG study protocol, n.d.).

The FLAG study has two groups of participants-the proband (older adults, 90 years or older, known to have exceptional longevity) and the offspring (progenies of the Proband group) (FLAG study protocol, n.d.). The current study sample consisted of participants drawn from the offspring group in the FLAG study. The inclusion criteria included age $(60+)$ and having data on social connectedness and perceived social support, the two independent variables examined in the current study. A total of 259 participants that met these inclusion criteria were included in the current study.

Data on social connectedness, perceived social support, and the health of older adults were analyzed with the purpose of understanding the relationship between the dimensions of social connectedness and perceived social support and health. The study was approved by the University of Utah Institutional Review Board (Ethics Committee reference \#: IRB 00011975).

\subsection{Measures}

\subsubsection{Independent Variables}

Social connectedness. Social connectedness was measured with the Duke Social Support Index (DSSI). Designed for use with older adults, the DSSI, with 10 items, offers a measure of the level or degree of a person's connectedness with others [30]. The DSSI has 10 items that were used to compute the two dimensions of connectedness, network, and satisfaction with the network. The network domain comprised three items which measure the frequency of interaction between participants and their family, friends, and neighbors during the past week. The responses ranged from none to seven times or more. The responses were recoded into $0=$ none to $5=$ seven or more times, during the past week, with scores ranging from 0 to 15. A higher score indicates a strong connection to members of one's network. The satisfaction with the network domain comprised five items which asked participants to indicate how satisfied they were with the relationships they have with family and friends. Reponses ranged from $1=$ hardly ever to $5=$ most of the time, with scores ranging from 5 to 25. A higher score indicates a greater level of satisfaction with one's network. Cronbach's alpha coefficients of 0.684 and 0.738 were recorded for the network and satisfaction with the network dimensions, respectively [30].

Perceived social support. Perceived social support was measured with the Duke-UNC Functional Social Support (DUNCFSS) questionnaire developed to provide a brief assessment of functional social support. It was designed specifically to measure an individual's perception of the amount and type of personal social support [31]. The instrument has 10 items with five-point Likert scale responses from 1 (much less than I would) to 5 (as much as I would like to). The 10 items were further grouped into 3 subscales (dimensions) measuring affective support, confidant support, and instrumental support. Affective support comprised three items with scores ranging from 3 to 15; confidant support comprised three items with scores ranging from 3 to 15; and instrumental support comprised four items with scores ranging from 4 to 20 . A higher score indicates strong affective, confidant, and instrumental support. Cronbach's alpha coefficients of $0.825,0.741$, and 0.686 were recorded for affective, confidant, and instrumental support, respectively $[32,33]$.

\subsubsection{Dependent Variables}

Physical and mental health. Physical and mental health were measured with the Medical Outcome Study Short-Form 36 (SF-36). The 36 items were used to compute 8 domains of health. The physical health domain had 10 items which required participants to describe the extent to which their health limits them in performing certain activities. Response 
categories ranged from $1=$ Yes, limited a lot to $3=$ No, not limited at all. All 10 items were recoded so that $1=0$ and $3=100$. Scores on physical health domain ranged from 0 to 100. A higher score indicates favorable physical health status. The mental health domain involved 5 questions requiring participants to indicate how they felt and how things have been with them over the last 4 weeks on a 6-point Likert scale response, $1=$ All of the time to $6=$ Most of the time. Items on this domain were recoded so that $1=0$ and $6=100$, with scores ranging from 0 to 100 . A higher score indicates a favorable health mental status. Cronbach's alpha coefficients of 0.75 and 0.81 were recorded for both physical and mental health, respectively $[34,35]$.

Covariates. Covariates included six items asking participants about their age, gender, marital status, living arrangements, socio-economic status, and religiosity. Age was a continuous variable that ranged from 60 to 81 years. Gender was a categorical variable with two response categories, $0=$ Male, and $1=$ Female. Marital status was a categorical variable with two response categories, $0=$ Not married $/$ single and $1=$ Married. Living arrangement was a categorical variable with two response categories, $0=$ Living alone and 1 = Living with others. Socio-economic status (SES) measured in terms of a family's gross income was a continuous variable ranging from USD 10,000 to USD 100,000 or more. SES was recoded into categorical variable with two response categories, $0=$ Poor to fair, representing individuals with family gross income less than USD 49,999, and $1=$ Good, representing participants with family gross income of USD 50,000 or more.

\subsection{Sample Characteristics}

The mean age of the sample was 67.75 years, with a range from 60 to 81 years. More than half $(58.7 \%)$ of the participants were female. Most $(84.2 \%)$ were married, and the majority (69.4\%) reported a good socio-economic status. More than two-thirds (90.3\%) indicated that they lived with others (spouse, children, siblings) (see Table 1).

Table 1. Socio-demographic characteristics of the study participants.

\begin{tabular}{ccccc}
\hline & Categories & $\mathbf{N}$ & \% & M \pm SD \\
\hline Age & - & 259 & - & $67.75 \pm 4.82$ \\
Gender & Male & 107 & 41.3 & - \\
Marital status & Female & 152 & 58.7 & - \\
& Unmarried/single & 41 & 15.8 & - \\
Socio-economic status & Married & 218 & 84.2 & - \\
& Poor-Fair & 79 & 30.6 & - \\
Living arrangement & Good & 179 & 69.4 & \\
& Alone & 25 & 9.7 & \\
\hline
\end{tabular}

Note: Because of missing data $\mathrm{N}$ is not always equal to 259.

Mean scores $(\mathrm{M}=7.42, \mathrm{SD}=1.55)$ and $(\mathrm{M}=12.89, \mathrm{SD}=1.64)$ were recorded for network and satisfaction with the network dimensions of social connectedness, respectively (see Table 2). Based on the mean scores, the participants appeared to have strong social connections, and were highly satisfied with their social connections. Mean scores for the three dimensions of social support were affective support $(\mathrm{M}=8.70, \mathrm{SD}=1.45)$, confidant support $(\mathrm{M}=9.27, \mathrm{SD}=2.23)$, and instrumental support $(\mathrm{M}=10.54, \mathrm{SD}=2.89)$. Based on the mean scores, the participants perceived the support they received from others as good. The sample's mean scores on the SF-36 scale were physical health $(\mathrm{M}=83.57 \mathrm{SD}=15.17)$ and mental health $(\mathrm{M}=74.65, \mathrm{SD}=12.17)$. Participants on average considered their health on both domains as good (see Table 2). 
Table 2. Mean scores of social connectedness, perceived social support, and health measures.

\begin{tabular}{|c|c|c|c|c|c|}
\hline & $\mathbf{N}$ & Mean & SD & Range & Score Cut-Off \\
\hline \multicolumn{6}{|l|}{ Social connectedness } \\
\hline Network & 259 & 7.42 & 1.55 & $3-15$ & $\geq 8$-high \\
\hline $\begin{array}{l}\text { Satisfaction with network } \\
\text { Social support }\end{array}$ & 257 & 12.89 & 1.64 & $6-21$ & $\geq 13$-high \\
\hline Affective support & 259 & 8.70 & 1.45 & $4-15$ & $\geq 9$-high \\
\hline Confidant support & 259 & 9.57 & 2.23 & $5-15$ & $\geq 10-$ high \\
\hline $\begin{array}{l}\text { Instrumental support } \\
\text { Health }\end{array}$ & 259 & 10.12 & 2.89 & $4-20$ & $\geq 10-$ high \\
\hline Physical health & 259 & 83.57 & 15.17 & $10-100$ & - \\
\hline Mental health & 259 & 74.92 & 12.17 & 28-92 & - \\
\hline
\end{tabular}

For the purposes of analysis, using the mean scores as the cut-off point, the participants were further divided into two groups based on their scores on the dimensions of social connectedness and social support. For social connectedness, a score $\geq 8$ on network dimension put a participant in a high network category and a score $\geq 13$ put one in a high satisfaction with network category. For social support, a score $\geq 10$ on both confidant and instrumental dimension put one in the category of high confidant and instrumental support, and a score $\geq 9$ on affective dimension put a participant in the high affective support category (see Table 2).

\subsection{Statistical Analysis}

The data were processed using Statistical Package for the Social Sciences (SPSS Statistics 25). Several statistics were used in the study, including the estimation of sample means and proportions according to the type of variables and regression analyses. A hierarchical regression analysis was used to examine the ability of the independent and covariate variables to predict the dependent variables. Using an independent samples $t$-test, the mean scores of the sample on health variables were compared in relation to the dimensions of social connectedness and perceived social support. Effect sizes (eta squared $-0.01=$ small effect; 0.06 = moderate effect; 0.10 = large effect) were calculated to determine the magnitude of the difference between the groups used in the independent samples $t$-test analysis.

\section{Results}

This section is divided by subheadings. It should provide a concise and precise description of the experimental results, their interpretation, as well as the experimental conclusions that can be drawn.

\subsection{Group Comparison}

\subsubsection{Social Connectedness and Physical and Mental Health}

An independent samples $t$-test was used to examine the differences in the dependent variables in relation to the independent variables. There were no statistically significant differences in the mean physical health score between participants who had a high network score $(\mathrm{M}=83.70, \mathrm{SD}=14.782)$ and those with a low network score $(\mathrm{M}=82.07, \mathrm{SD}=16.707)$, $t(257)=-0.768, p=0.443$; and mean mental health scores between the participants who had a high network score $(\mathrm{M}=74.71, \mathrm{SD}=12.539)$ and those with a low network score $(\mathrm{M}=74.56, \mathrm{SD}=13.866), t(257)=-0.084, p=0.933$ (see Table 3$)$. The results, however, showed statistically significant differences in the mean physical and mental health scores between participants who had a high satisfaction with network score and those who had a low satisfaction score. For physical health, participants with a high satisfaction with network scores had a significantly higher physical health score $(\mathrm{M}=84.53, \mathrm{SD}=13.628)$, compared to those with a low satisfaction with network score $(\mathrm{M}=80.76, \mathrm{SD}=18.816)$, $t(257)=-2.02, p<0.05$. The magnitude of the difference in mean score was 3.77, with a small effect size $($ Eta squared $=0.015)$. For mental health, participants with a high 
satisfaction with network score had a significantly higher mental health score ( $\mathrm{M}=77.37$, $\mathrm{SD}=11.163)$, compared to those with a low satisfaction with network score $(\mathrm{M}=67.76$, $\mathrm{SD}=14.531), t(257)=-5.571, p<0.001$. The magnitude of the difference in the mean score was 9.61 , with a moderate effect size (Eta squared $=0.081$ ). Generally, older participants who were more satisfied with their network were more likely to have better physical and mental health compared to those who were less satisfied with their network.

Table 3. Means score differences in physical and mental health in relation to the dimensions of social connectedness ( $t$-test).

\begin{tabular}{lccccc}
\hline \multicolumn{5}{c}{ Social Connectedness Dimensions } \\
\hline
\end{tabular}

\subsubsection{Perceived Social Support and Physical and Mental Health}

An independent samples t-test showed statistically significant differences in the mean physical and mental health scores between the participants who had high affective, confidant, and instrumental support and those with low support on these dimensions (see Table 4). For physical health, participants with a high affective support score had a significantly higher physical health score $(\mathrm{M}=85.78, \mathrm{SD}=13.577)$, compared to those with a low affective support score $(\mathrm{M}=79.57, \mathrm{SD}=17.059), t(257)=-3.211, p<0.001$; participants with a high confidant support score had a significantly higher physical health score $(\mathrm{M}=85.51, \mathrm{SD}=13.692)$, compared to those with a low confidant support score $(\mathrm{M}=80.63$, $\mathrm{SD}=16.813), t(257)=-2.562, p<0.01$; and participants with a high instrumental support score had a significantly higher physical health score $(\mathrm{M}=86.27, \mathrm{SD}=12.084)$, compared to those with a low affective support score $(\mathrm{M}=79.13, \mathrm{SD}=18.417), t(257)=-3.767, p<0.001$. The magnitude of the difference in the mean score ranged from -4.882 to -7.141 , with small to moderate effect sizes (Eta squared $=0.025-0.053$ ).

Table 4. Mean score differences in physical and mental health in relation to the dimensions of perceived social support ( $t$-test).

\begin{tabular}{|c|c|c|c|c|c|c|c|c|c|}
\hline \multicolumn{10}{|c|}{ Social Support Dimensions } \\
\hline & \multicolumn{2}{|c|}{ Affective } & & \multicolumn{2}{|c|}{ Confidant } & \multicolumn{4}{|c|}{ Instrumental } \\
\hline & $\begin{array}{c}\text { High } \\
(\mathrm{n}=167)\end{array}$ & $\begin{array}{c}\text { Low } \\
(\mathrm{n}=92)\end{array}$ & $t$ & $\begin{array}{c}\text { High } \\
(\mathrm{n}=156)\end{array}$ & $\begin{array}{c}\text { Low } \\
(\mathrm{n}=103)\end{array}$ & $t$ & $\begin{array}{c}\text { High } \\
(\mathrm{n}=154)\end{array}$ & $\begin{array}{c}\text { Low } \\
(\mathrm{n}=89)\end{array}$ & $t$ \\
\hline & M & M & & M & M & & $M$ & M & \\
\hline Health & & & & & & & & & \\
\hline Physical health & 85.78 & 79.57 & $-3.211^{* *}$ & 85.51 & 80.63 & $-2.562 * *$ & 86.27 & 79.13 & $-3.767^{* * *}$ \\
\hline Mental health & 78.28 & 68.83 & $-6.078^{* * *}$ & 78.11 & 70.10 & $-5.175^{* * *}$ & 78.49 & 69.06 & $-6.152^{* * *}$ \\
\hline
\end{tabular}

In terms of mental health, participants with a high affective support score had a significantly higher mental health score $(\mathrm{M}=78.28, \mathrm{SD}=11.231)$, compared to those with a low affective support score $(\mathrm{M}=68.83, \mathrm{SD}=13.240), t(257)=-6.078, p<0.001$; participants with a high confidant support score had a significantly higher mental health score $(\mathrm{M}=78.11, \mathrm{SD}=11.852)$, compared to those with a low confidant support score $(\mathrm{M}=70.10$, $\mathrm{SD}=12.697), t(257)=-5.175, p<0.001$; and participants with a high instrumental support 
score had a significantly higher mental health score $(\mathrm{M}=78.49, \mathrm{SD}=10.638)$, compared to those with a low instrumental support score $(M=69.06, S D=13.875), t(257)=-6.152$, $p<0.001$. The magnitude of the difference in the mean score ranged from -8.012 to -9.455 , with moderate to large effect sizes (Eta squared $=0.095-0.135)$ (see Table 4 ). In summary, older adults who perceived that they were receiving more affective, confidant, and instrumental support were more likely to have better physical and mental health than those who perceived that they were receiving minimal affective, confidant, and instrumental social support.

\subsection{Hierarchical Regression Analysis}

\subsubsection{Predictors of Physical Health}

Table 5 presents the results from the hierarchical regression analyses examining the effects of social connectedness and social support on physical health, after controlling for the influence of socio-demographic variables. Model 1 examined the effects of all five of the socio-demographic variables on physical health. The model with all the variables was significant, $F(5,250)=3.829, p<0.01$, and explained $7.1 \%(R$-squared $=0.071)$ of the total variance in physical health. Age $(B=-0.480, p=0.016)$ and socio-economic status $(B=4.314, p<0.05)$ significantly predicted physical health $(R$-square change $=0.071$, $p<0.05)$. The remaining demographic variables were not associated with physical health $(p>0.05)$ (see Table 5).

Table 5. Coefficients and standard errors from the regression of physical health scores on the covariates and independent variables.

\begin{tabular}{|c|c|c|c|}
\hline Variables & Model 1 & Model 2 & Model 3 \\
\hline \multicolumn{4}{|l|}{ Demographics } \\
\hline Age $^{\text {a }}$ & $-0.480 *(0.198)$ & $-0.566^{* *}(0.200)$ & $-0.616^{* *}(0.200)$ \\
\hline Gender $b(\mathrm{i})$ & $-3.259(1.932)$ & $-3.674 *(1.931)$ & $-3.898 *(1.990)$ \\
\hline Marital status ${ }^{b}$ & $0.2 .63(3.722)$ & $0.233(3.695)$ & $-1.104(3.685)$ \\
\hline Living arrangement ${ }^{b}$ & $1.779(4.478)$ & $1.226(4.455)$ & $1.012(4.412)$ \\
\hline SES b(ii) & $4.314 *(2.167)$ & $3.868 *(2.158)$ & $3.076 *(2.160)$ \\
\hline \multicolumn{4}{|l|}{ Social Connectedness } \\
\hline Network $^{a}$ & & $0.510(1.178)$ & $0.292(1.171)$ \\
\hline Satisfaction ${ }^{a}$ & & $1.326 *(0.609)$ & $-0.253(0.738)$ \\
\hline \multicolumn{4}{|l|}{ Social support } \\
\hline Affective $^{\text {a }}$ & & & $3.506^{* *}(2.883)$ \\
\hline Confidant ${ }^{\mathrm{a}}$ & & & $0.20(0.517)$ \\
\hline Instrumental $^{\mathrm{a}}$ & & & $0.521(0.448)$ \\
\hline $\mathrm{R}$ & 0.267 & 0.305 & 0.356 \\
\hline $\mathrm{R}^{2}$ & 0.071 & 0.093 & 0.127 \\
\hline Adjusted $\mathrm{R}^{2}$ & 0.053 & 0.067 & 0.091 \\
\hline $\mathrm{R}^{2}$ Change & 0.071 & 0.022 & 0.034 \\
\hline Intercept & $7.851^{* * *}$ & $5.414^{* * *}$ & $5.383^{* * *}$ \\
\hline Unweighted $\mathrm{N}$ & 256 & 256 & 256 \\
\hline $\mathrm{F}$ & $3.829 * *$ & $3.624^{* *}$ & $3.564^{* * *}$ \\
\hline $\mathrm{df}($ residual) & $5(250)$ & $7(248)$ & $10(245)$ \\
\hline
\end{tabular}

Notes: ${ }^{*} p<0.05 ;{ }^{* *} p<0.01 ;{ }^{* *} p<0.001$. SES $=$ Socio-economic status. ${ }^{\text {a }}$ Continuous variable. ${ }^{\mathrm{b}}$ Dichotomous variable. ${ }^{i}$ Reference category is female. ${ }^{\text {ii }}$ Reference category is good SES. Unstandardized regression coefficients shown. Standard errors are presented in parenthesis. A higher significant positive coefficient indicates better physical health.

Model 2 examined the effect of network and satisfaction with network (the two dimensions of social connectedness) on physical health, after controlling for the effects of sociodemographic variables. The model was significant, $F(7,248)=3.624, p<0.001$, explaining $9.3 \%$ of the total variance in physical health. Satisfaction with network $(B=1.326, p<0.05)$ significantly predicted physical health $(R$-square change $=0.022, F$-change $(2,248)=2.963$, $p<0.05$, after controlling for the effects of socio-demographic variables. 
The dimensions of social support-affective, confidant, and instrumental support-were introduced in model 3. Their inclusion enhanced the model's performance in predicting physical health, with the model as a whole explaining $12.7 \%$ of the total variance in physical health, $R$-square $=0.127, F(10,245)=3.564, p<0.001$. Affective support $(B=1.506, p<0.05)$ significantly predicted physical health, and helped explain $3.4 \%$ of the variance in physical health, $R$-square change $=0.034, F$-change $=(3,245)=3.200, p<0.001$. Confidant and instrumental support were not significant predictors of physical health. $R$ was significantly different from zero at the end of each model. None of the dimensions of social connectedness were associated with physical health following the introduction of the perceived support dimensions. Age $(B=-0.616, p<0.01)$, gender $(B=-3.898, p<0.05)$ and SES $(B=3.076, p<0.05)$ were significant predictors of physical health (see Table 5$)$. While one dimension of perceived social support significantly predicted physical health, none of the dimensions of social connectedness predicted physical health.

\subsubsection{Predictors of Mental Health}

Table 6 presents the results from the hierarchical regression analyses examining the effects of social connectedness and social support on mental health, after controlling for the effects of socio-demographic variables. All five of the socio-demographic variables were entered in model 1 . The model with all demographic variables was not significant $F(5,250)=1.854, p=0.103$. However, age $(B=0.394, p<0.05)$ was a significant predictor of mental health, which explained $3.6 \%(R$-square $=0.036, p<0.05)$ of the total variance in mental health. The rest of the demographic variables were not associated with mental health $(p>0.05)$ (see Table 6).

Table 6. Coefficients and standard errors from the regression of mental health scores on the covariates and independent variables.

\begin{tabular}{|c|c|c|c|}
\hline Variables & Model 1 & Model 2 & Model 3 \\
\hline \multicolumn{4}{|l|}{ Demographics } \\
\hline $\operatorname{Age}^{a}$ & $0.3 .94^{* *}(0.170)$ & $0.97(0.158)$ & $0.361(0.117)$ \\
\hline Gender $b(\mathrm{i})$ & $-2.104(1.658)$ & $-3.082 *(1.528)$ & $-3.487^{* *}(1.490)$ \\
\hline Marital status ${ }^{b}$ & $0.240(3.194)$ & $0.185(2.942)$ & $-2.061(2.758)$ \\
\hline Living arrangement ${ }^{b}$ & $-0.647(3.843)$ & $-0.604(3.525)$ & $-7.83(3.303)$ \\
\hline SES b(ii) & $1.652(2.823)$ & $1.620(1.708)$ & $0.725(1.617)$ \\
\hline \multicolumn{4}{|l|}{ Social Connectedness } \\
\hline Network $^{a}$ & & $1.043(0.932)$ & $0.853(0.876)$ \\
\hline Satisfaction ${ }^{a}$ & & $3.308^{* * *}(0.482)$ & $1.627^{* *}(0.552)$ \\
\hline \multicolumn{4}{|l|}{ Social support } \\
\hline Affective $^{\text {a }}$ & & & $3.167^{* * *}(0.755)$ \\
\hline Confidant $^{\mathrm{a}}$ & & & $-0.367(0.387)$ \\
\hline Instrumental ${ }^{a}$ & & & $0.830 *(0.355)$ \\
\hline $\mathrm{R}$ & 0.189 & 0.446 & 0.557 \\
\hline $\mathrm{R}^{2}$ & 0.036 & 0.199 & 0.310 \\
\hline Adjusted $\mathrm{R}^{2}$ & 0.016 & 0.177 & 0.282 \\
\hline $\mathrm{R}^{2}$ Change & 0.036 & 0.164 & 0.111 \\
\hline Intercept & $3.784^{* * *}$ & -0.127 & -0.245 \\
\hline Unweighted N & 256 & 256 & 256 \\
\hline $\mathrm{F}$ & 1.854 & $8.819^{* * *}$ & $11.029^{* * *}$ \\
\hline df(residual) & $5(250)$ & $7(248)$ & $10(245)$ \\
\hline
\end{tabular}

Notes: ${ }^{*} p<0.05 ;{ }^{* *} p<0.01 ;{ }^{* * *} p<0.001$. SES $=$ Socio-economic status. ${ }^{\text {a }}$ Continuous variable. ${ }^{\mathrm{b}}$ Dichotomous variable. ${ }^{i}$ Reference category is female. ${ }^{\text {ii }}$ Reference category is good SES. Unstandardized regression coefficients shown. Standard errors are presented in parenthesis. A higher significant positive coefficient indicates better mental health.

Model 2 examined the effect of the dimensions of social connectedness-network and satisfaction with network-on mental health. The model was significant $F(7,248)=8.819$, $p<0.001$. Including both dimensions improved the model's performance in predicting mental health, with this model explaining $19.9 \%$ of the variance in mental health, 
$R$-square $=0.199$. Of the two dimensions, satisfaction with network significantly predicted mental health and explained $16.4 \%$ of the variance in mental health, $R$-square change $=0.164$, $F$-change $(2,248)=25.331, p<0.001$, after controlling for the demographic variables.

The dimensions of social support-affective, confidant and instrumental-were entered in model 3. The model was significant $F(10,208)=8.573, p<0.001$. Their inclusion also enhanced the model's performance in predicting mental health, with the model as a whole explaining $28.2 \%$ of the total variance in mental health, $R$-square $=0.292$. Affective $(B=3.167, p<0.001)$ and instrumental $(B=2.713, p<0.05)$ support were significant predictors of mental health. Both dimensions explained an additional $11.1 \%$ of the total variance in mental health after controlling for the influence of socio-demographic variables and the dimensions of social connectedness, $R$-square change $=0.111, F$-change $(3,245)=13.158$, $p<0.001$.

Model 3 highlights the predictive ability of satisfaction with network. Together, satisfaction with network, and affective and instrumental support were significant predictors of mental health.

\section{Discussion}

The findings that social connectedness and social support were related to health status of older adults did not come as a surprise. Most of the analyses showed that connectedness and support dimensions had significant, positive, small-to-medium in-strength associations with the health of older adults. Consistent with previous research $[11,12,25,28]$, the findings of the current study further highlight the multidimensionality of social connectedness and social support constructs, suggesting that different aspects of these constructs are related in different ways to health and wellbeing in older adults. A social network provides the context within which people can interact with one another, thereby leading to the perception of being socially connected $[6,11,19]$. The importance of the social network cannot be underestimated as a mechanism through which productive and healthy aging occurs and acts as protection against many health and behavioral limitations that could compromise quality of life of older adults $[3,10,21,26]$. Contrary to expectations, however, the findings of this study showed no significant association between the network dimension of the social connectedness and physical and mental health. There was no significant difference in the mean physical and mental health scores between participants with a high network score and those with a low network score. In other words, the physical and mental health status of participants who were highly connected were not significantly different from those who were less connected. The degree of connectedness has often been measured by network size, frequency of interaction with others, and participation in social activities [12]. Interestingly, previous studies, for the most part, have documented a range of findings, from a lack of significant association to significant positive or negative associations, between these measures of connectedness and health variables studied [26,36,37]. In the research community, the consensus, following these mixed findings, has been that to the older adult, the number of interactions, for instance, is not as important to them as the quality of the interaction [38]. To the participants in the current study, it is probably not the existence of people they could count as forming their social ties or having frequent interactions with that is important, but rather the satisfaction they derive from their network that matters to them.

Although not significant, the direction of the association between physical and mental health and the network dimension leaves much to be desired. In contrast to most previous studies, the results of the present study seemed to suggest a possible negative impact of the network on the health status of older adults. This finding is consistent with studies by Antonucci et al. [36] and Perkins et al. [26] which suggested that the negative consequences of a social network on health may arise from demands placed on older adults with little or no resources to meet the demands. The findings of these studies $[26,36]$ showed that participants who reported a larger network size, with a resulting frequent interaction and increase in demands, were less happy and had a poorer health status than those who 
reported a smaller network size. Similar to the group difference analysis which found no significant differences in the mean physical and mental health scores between participants with a high and low network, the hierarchical regression analysis also showed that network was not a significant predictor of either physical or mental health when the effects of demographic variables were controlled for.

Satisfaction with the social network is important because it represents a person's overall assessment of quality and quantity of social contacts available to the individual. Satisfaction with a network can be measured in terms of the amount of support a person receives. This, however, suggests the possibility of rating as high a person's level of connectedness irrespective of one's network characteristics (e.g., frequency of interaction). Significant associations were found between the satisfaction component of the social connectedness scale and health measures, with high scores on satisfaction with network corresponding with high physical and mental health scores. Consistent with findings of earlier research [28], the findings of the current study suggest that participants who were more satisfied with their social ties (as measured in terms of support received) had better physical and mental health, compared to those who were less satisfied. The associations between the satisfaction dimensions and the health of older adults underscore the value older adults attach to the quality rather than the quantity of social ties $[3,6,38]$. The finding that affective support was significantly associated with physical and mental health is consistent with the findings of Antonucci et al. [18] and Chao [28]. Operating through social and psychological pathways, affective support has been documented to greatly improve older adults' health [25]. To many older adults, having family and close friends who exhibit a caring and compassion attitude toward them and engage them both socially and cognitively by facilitating social and pleasurable activities with them, gives them the feeling that they are liked, accepted, and understood $[13,18]$. The opportunity to stay connected with others and obtain the necessary affective support helps combat feelings of loneliness and isolation which are risk factors of mental illness in the adult population [39].

The findings of this research confirm previous studies which indicate that instrumental support is more often provided by family and tends to be associated with the improved health status of older adults $[8,28]$. Instrumental support comes in many forms. For some older adults, it is about family, carers, and friends finding information and coordinating services for them [40]. For others, it comes in the form of receiving assistance with daily activities [41]. Yet for some, instrumental support assumes a whole different meaning as it is interpreted in emotional terms. To such individuals, instrumental support connotes the idea of caring, esteeming, and understanding an individual. Instrumental support is simply understood as any behavior or action perceived by the support recipient as helpful [29]. Regardless of the form it takes, the availability of instrumental support is reported to be associated with improved mental health and decreased financial and economic stress, making older adults feel relaxed and happier [42]. With nearly 90 percent of the sample indicating they lived with others, possibly with spouses, children, siblings, or any other extended relatives, the finding that the provision of instrumental support was associated with good mental health only seemed confirmatory. The results of this study, however, showed that the dimensions of social support had stronger associations than the dimensions of social connectedness to the health status of older adults. While this reflects participants' regard for social support rather than the frequency of interaction or the number of people in their network, this finding clearly shows social support is important to health in late life. Future studies may, however, investigate the underlying factors responsible for these differential associations of social connectedness and social support to the health and wellbeing of older adults. In a nutshell, the perceived availability of social support, in any form, can be a source of a general positive affect, enhanced self-worth, and feelings of being socially connected and protected. Similarly, research also documents situations where excessive support provision negatively affected the health and wellbeing older adults. Seeman [43], for instance, found that the provision of instrumental support, which was well intended, caused a deterioration in the physical and mental health of 
older adults, as it weakened older adults' confidence to remain independent. The findings of this study, in confirming earlier research, underscore the need to not only ensure the integration of older adults but also ensure they receive the needed support to live normal and healthy lives.

\subsection{Limitations}

The findings of this study add to the existing literature on social relationships and health in the adult population. Contrary to the popular notion on the importance of social connectedness to health, the findings of this study implicitly suggest that the effect of social connectedness on the health of older adults operates through social support. Contributing to the existing literature, the findings of this study highlight the importance of social support in relation to the health of older adults. In spite of this, the results of this study must be interpreted with caution, as the socio-demographic characteristics of the participants may have influenced the results of the study. Most of the participants in this study were females in their mid to late 60 s who were married, lived with others, and had a good SES. A combination of these characteristics, for instance, being a female with a good socio-economic status, and living with others, has the potential to influence the health-seeking behavior and health outcomes of an individual [44,45]. It is suspected that these demographic variables included in the analysis may have influenced the results of the current study. In choosing participants with data on the independent variables of interest, a selection bias may have been introduced. The sample selected for analysis may not be representative or accurately reflect the target population. The results of the study may have been skewed due to selection bias, thereby limiting the generalizability of the study's findings. Relatedly, participants in the study may also be significantly different from older adults living in other states of America or countries around the world. This also places a limitation on the findings thereby limiting their generalizability. Social connectedness and perceived social support have both been found to be associated with health. A correlation rather than a predictive association has been reported in almost all studies examining the association between social relationships and health. Correlation does not imply causation. As a cross-sectional study, this research is limited by the fact that correlation, but not causality, could only be determined. It is, therefore, not possible to determine if the dimensions of social connectedness and perceived social support examined in the study could lead to better health or poor health among older adults.

\subsection{Implications}

In an era characterized by health promotion activities and with the healing quality that relationships possess, studies of this nature have become essential. The outcome of this study has implications for social work practice and education, policy, and research.

\subsubsection{Social Work Practice}

While interventions are constantly being developed to offer relief from health problems, the outcome of this study is valuable in designing practice interventions intended to increase not only social support, but also to improve social ties through which support is offered. It is believed that strong ties and adequate support contribute to a greater sense of belonging and social fulfillment. Such interventions, therefore, will help alleviate the problem of isolation and loneliness that have almost been accepted as characteristic of aging.

\subsubsection{Social Work Education}

Addressing the many health complications and social problems people may be faced with in late life requires creating an awareness and developing effective training for a generation of health and human service professionals with the will to join in such efforts. With the surge in health promotion activities, particularly in the areas of non-conventional means of promoting health and wellbeing, the findings of this study are essential. It is im- 
portant that students join the global conversation around health and the non-conventional means of promoting it, of which social relationships are a major component. The findings of this study, therefore, might inform the training of social work students with a gerontology focus, who are educated to provide social and supportive service to help older adults to live independently or stay in the community.

\subsubsection{Policy}

The attempt to address the problem of isolation and loneliness may also be considered at the policy level. With findings supporting staying connected and supported influence an individual's health status, policy interventions might be designed and implemented with the aim of targeting older adults at risk of becoming socially isolated. A policy intervention may take the form of community employment opportunities for older adults. While the manifest function may be about enhancing the economic wellbeing of older adults, such policies may latently function to help older adults stay active and connected to other individuals in the community.

\subsubsection{Research}

Further research is needed to confirm the results and fill in the gaps identified in this study. While the findings of some previous studies have suggested that social connectedness is more important to the health and wellbeing of older adults than social support, the current study suggests otherwise. Previous studies have also documented the effects of demographic characteristics such as age and gender, and emotional states or wellbeing such as the presence or absence of depressive symptoms, on social relationships and social support. Since the current study did not include variables on the emotional wellbeing of participants and the analysis did not examine the effects of demographic characteristics on social connectedness and perceived social support, it is suggested that future research not only examine the effects of these variables but also their roles in the differential associations of social connectedness and social support with the health and wellbeing of older adults.

\section{Conclusions}

This study investigated the associations of the dimensions of social connectedness (network and satisfaction with network) and perceived social support (affective, confidant and instrumental support) with the physical and mental health among older adults in the Utah FLAG study. The results showed that significant differences existed in the physical and mental health of participants who were highly satisfied with their network, and received higher levels of affective, confidant, and instrumental support. Satisfaction with networks and instrumental and affective support remained significant predictors of both physical and mental health when the effects of demographic variables were controlled for. The findings generally suggest that social connectedness and perceived social support may affect different aspects of health independent of the other. The findings also suggest that perceived social support may be relatively more important to the health and wellbeing of older adults than social connectedness and underscore the relative importance older adults attach to the quality rather than quantity of social ties.

Author Contributions: S.A.: Conceptualization, Methodology, Formal Analysis, Writing-Original Draft Preparation. G.K.: Methodology, Writing-Review and Editing. All authors have read and agreed to the published version of the manuscript.

Funding: This research received no external funding.

Institutional Review Board Statement: This study was approved by the University of Utah Institutional Review Board (Ethics Committee reference \#: IRB 00011975).

Informed Consent Statement: This study was approved by the University of Utah Institutional Review Board, as part of a larger study called the Utah Study of Fertility, Longevity, and Aging (FLAG). Informed consent was obtained from all subjects involved in the study. 
Data Availability Statement: Not applicable.

Acknowledgments: The authors of this study are grateful to the FLAG (Fertility, Longevity, and Aging) research team for making available to us the FLAG study data used in this study. The authors are also grateful to Frances Wilby and Marilyn Luptak of the College of Social Work, University of Utah, who co-chaired the first author's doctoral dissertation, from which this study is adapted.

Conflicts of Interest: The authors declare no conflict of interest.

Disclaimer: The present study was adapted from the first author's doctoral dissertation submitted to the University of Utah.

\section{References}

1. Antonucci, T.C.; Birditt, K.S.; Ajrouch, K. Convoys of social relations: Past, present, and future. In Handbook of Life-Span Development; Fingerman, K.L., Berg, C.A., Smith, J., Antonucci, T.C., Eds.; Springer Publishing Co.: New York, NY, USA, 2011; pp. 161-182.

2. Holt-Lunstad, J.; Smith, T.B.; Layton, J.B. Social relationships and mortality risk: A meta-analytic review. PLoS Med. 2010, 7, e1000316. [CrossRef] [PubMed]

3. Valtorta, N.K.; Moore, D.C.; Barron, L.; Stow, D.; Hanratty, B. Older adults' social relationships and health care utilization: A systematic review. Am. J. Public Health 2018, 108, e1-e10. [CrossRef] [PubMed]

4. Chen, Y.; Hicks, A.; While, A.E. Loneliness and social support of older people in China: A systematic literature review. Health Soc. Care Community 2013, 22, 113-123. [CrossRef] [PubMed]

5. Steptoe, A.; Shankar, A.; Demakakos, P.; Wardle, J. Social isolation, loneliness, and all-cause mortality in older men and women. Proc. Natl. Acad. Sci. USA 2013, 110, 5797-5801. [CrossRef]

6. Rook, K.S.; Charles, S.T. Close social ties and health in later life: Strengths and vulnerabilities. Am. Psychol. 2017, 72, 567-577. [CrossRef]

7. Uchino, B.N. Understanding the links between social ties and health. J. Soc. Pers. Relatsh. 2012, 30, 155-162. [CrossRef]

8. Salinas-Rodríguez, A.; Moreno-Tamayo, K.; Hernández-Serrato, M.; Enríquez-Rosas, M.D.R.; Manrique-Espinoza, B. Multidimensional social support is associated with healthcare utilization among older Mexican adults. Eur. J. Ageing 2017, 15, 77-85. [CrossRef]

9. Aschbrenner, K.A.; Mueser, K.T.; Bartels, S.J.; Pratt, S.I. Family contact and health status among older adults with serious mental illnesses. Psychiatr. Rehabil. J. 2011, 34, 295-303. [CrossRef]

10. Ermer, A.E.; Proulx, C.M. Associations between social connectedness, emotional well-being, and self-rated health among older adults: Difference by relationship status. Res. Aging 2018, 41, 336-361. [CrossRef]

11. Beller, J.; Wagner, A. Disentangling loneliness: Differential effects of subjective loneliness, network quality, network size, and living alone on physical, mental, and cognitive health. J. Aging Health 2017, 30, 521-539. [CrossRef]

12. Cornwell, E.Y.; Waite, L.J. Social disconnectedness, perceived isolation, and health among older adults. J. Health Soc. Behav. 2009, 50, 31-48. [CrossRef]

13. Hodgkin, S.; Warburton, J.; Hancock, S. Predicting wellness among rural older Australians: A cross-sectional study. Rural Remote Health 2018, 18, 4547. [CrossRef]

14. Aboim, S.; Vasconcelos, P.; Wall, K. Support, social networks and the family in Portugal: Two decades of research. Int. Rev. Soc. 2013, 23, 47-67. [CrossRef]

15. Pedersen, P.V.; Andersen, P.T.; Curtis, T. Social relations and experiences of social isolation among socially marginalized people. J. Soc. Pers. Relatsh. 2012, 29, 839-858. [CrossRef]

16. Nigudkar, A.; Wandrekar, J.; Sovani, A.; Thatte, S. Social connectedness in ageing and its correlates: Emotional and cognitive health. Indian J. Gerontol. 2019, 33, 20-30.

17. Tomás, J.M.; Pinazo-Hernandis, S.; Oliver, A.; Donio-Bellegarde, M.; Tomás-Aguirre, F. Loneliness and social support: Differential predictive power on depression and satisfaction in senior citizens. J. Community Psychol. 2019, 47, 1225-1234. [CrossRef]

18. Antonucci, T.C.; Birditt, K.S.; Akiyama, H. Convoys of social relations: An interdisciplinary approach. In Handbook of Theories of Aging, 2nd ed.; Bengtson, V.L., Ed.; Springer Publishing Co.: New York, NY, USA, 2009; pp. 247-260.

19. Ashida, S.; Heaney, C.A. Differential associations of social support and social connectedness with structural features of social networks and the health status of older adults. J. Aging Health 2008, 20, 872-893. [CrossRef]

20. Nurullah, A.S. Received and provided social support: A review of current evidence and future directions. Am. J. Health Stud. 2012, 27, 173-188.

21. Harasemiw, O.; Newall, N.; MacKenzie, C.S.; Shooshtari, S.; Menec, V. Is the association between social network types, depressive symptoms and life satisfaction mediated by the perceived availability of social support? A cross-sectional analysis using the Canadian Longitudinal Study on Aging. Aging Ment. Health 2018, 23, 1413-1422. [CrossRef]

22. Wu, F.; Sheng, Y. Social support network, social support, self-efficacy, health-promoting behavior and healthy aging among older adults: A pathway analysis. Arch. Gerontol. Geriatr. 2019, 85, 103934. [CrossRef] 
23. Boateng, G.O.; Neilands, T.B.; Frongillo, E.A.; Melgar-Quiñonez, H.R.; Young, S.L. Best Practices for Developing and Validating Scales for Health, Social, and Behavioral Research: A Primer. Front. Public Health 2018, 6, 149. [CrossRef] [PubMed]

24. Morgado, F.F.R.; Meireles, J.F.F.; Neves, C.M.; Amaral, A.C.S.; Ferreira, M.E.C. Scale development: Ten main limitations and recommendations to improve future research practices. Psicol. Reflexão Crítica 2017, 30, 1-20. [CrossRef] [PubMed]

25. Wong, S.T.; Wu, A.; Gregorich, S.; Pérez-Stable, E.J. What type of social support influences self-reported physical and mental health among older women? J. Aging Health 2014, 26, 663-678. [CrossRef] [PubMed]

26. Perkins, M.M.; Ball, M.M.; Kemp, C.L.; Hollingsworth, C. Social relations and resident health in assisted living: An application of the convoy model. Gerontologist 2012, 53, 495-507. [CrossRef]

27. Van Bel, D.T.; Smolders, K.C.H.J.; IJsselsteijn, W.A.; De Kort, Y.A.W. Social connectedness: Concept and measurement. In Proceedings of the International Conference on Intelligent Environments, Barcelona, Spain, 20-21 July 2009; pp. 67-74. [CrossRef]

28. Chao, S.F. Assessing social support and depressive symptoms in older Chinese adults: A longitudinal perspective. Aging Ment. Health 2011, 15, 765-774. [CrossRef]

29. Semmer, N.K.; Elfering, A.; Jacobshagen, N.; Perrot, T.; Beehr, T.A.; Boos, N. The emotional meaning of instrumental social support. Int. J. Stress Manag. 2008, 15, 235-251. [CrossRef]

30. Pachana, N.A.; Smith, N.; Watson, M.; McLaughlin, D.; Dobson, A. Responsiveness of the Duke Social Support sub-scales in older women. Age Ageing 2008, 37, 666-672. [CrossRef]

31. Saracino, R.; Kolva, E.; Rosenfeld, B.; Breitbart, W. Measuring social support in patients with advanced medical illnesses: An analysis of the Duke-UNC Functional Social Support Questionnaire. Palliat. Support. Care 2014, 13, 1153-1163. [CrossRef]

32. Broadhead, W.; Gehlbach, S.H.; de Gruy, F.V.; Kaplan, B.; Gorst-Unsworth, C.C.; Goldenberg, E.E. Duke-UNC Functional Social Support Questionnaire. Br. J. Psychiatry 1998, 172, 90-94. [CrossRef]

33. Mas-Expósito, L.; Amador-Campos, J.; Gómez-Benito, J.; Lalucat-Jo, L. Validation of the modified DUKE-UNC Functional Social Support Questionnaire in patients with schizophrenia. Soc. Psychiatry 2012, 48, 1675-1685. [CrossRef]

34. Bunevicius, A. Reliability and validity of the SF-36 Health Survey Questionnaire in patients with brain tumors: A cross-sectional study. Health Qual. Life Outcomes 2017, 15, 1-7. [CrossRef]

35. Arovah, N.I.; Heesch, K.C. Verification of the reliability and validity of the Short Form 36 Scale in Indonesian middle-aged and older adults. J. Prev. Med. Public Health 2020, 53, 180-188. [CrossRef]

36. Antonucci, T.C.; Akiyama, H.; Lansford, J.E. Negative effects of close social relations. Fam. Relat. 1998, 47, 379. [CrossRef]

37. Umberson, D.; Montez, J.K. Social relationships and health: A flashpoint for health policy. J. Health Soc. Behav. 2010, 51, S54-S66. [CrossRef]

38. Teo, A.R.; Choi, H.; Valenstein, M. Social relationships and depression: Ten-year follow-up from a nationally representative study. PLoS ONE 2013, 8, e62396. [CrossRef]

39. CDC. The State of Mental Health and Aging in America. 2008. Available online: http://www.cdc.gov/aging/pdf/mental_health. pdf (accessed on 7 November 2021).

40. Abdi, S.; Spann, A.; Borilovic, J.; De Witte, L.; Hawley, M. Understanding the care and support needs of older people: A scoping review and categorisation using the WHO international classification of functioning, disability and health framework (ICF). BMC Geriatr. 2019, 19, 195. [CrossRef]

41. Nicholson, C.; Meyer, J.; Flatley, M.; Holman, C.; Lowton, K. Living on the margin: Understanding the experience of living and dying with frailty in old age. Soc. Sci. Med. 2012, 75, 1426-1432. [CrossRef]

42. Jiang, L.; Drolet, A.; Kim, H.S. Age and social support seeking: Understanding the role of perceived social costs to others. Pers. Soc. Psychol. Bull. 2018, 44, 1104-1116. [CrossRef]

43. Seeman, T.E. Social ties and health: The benefits of social integration. Ann. Epidemiol. 1996, 6, 442-451. [CrossRef]

44. Carmel, S. Health and well-being in late life: Gender differences worldwide. Front. Med. 2019, 6, 218. [CrossRef]

45. Vlassoff, C. Gender differences in determinants and consequences of health and illness. J. Health Popul. Nutr. $2007,25,47-61$. 